\title{
25C-NBOMe short characterisation
}

\author{
Katarzyna Kamińska ${ }^{1} \cdot$ Paweł Świt $^{1} \cdot$ Kamilla Malek $^{2}$
}

Received: 26 December 2019 / Accepted: 15 March 2020 / Published online: 30 March 2020

(c) The Author(s) 2020

\begin{abstract}
Purpose $\mathrm{N}$-Methoxybenzyls, a group of toxic phenylethylamine derivatives of the $2 \mathrm{C}$ family compounds, are a new class of potent serotonin 5- $\mathrm{HT}_{2 \mathrm{~A}}$ receptor agonist hallucinogens with potential harmful effects. This study summarizes current state of knowledge of one of the most dangerous representative of this group- $\mathrm{N}$-(2-methoxybenzyl)-2,5-dimethoxy-4-chlorophenethylamine (25C-NBOMe). Due to hallucinogenic properties similar to those observe after lysergic acid diethylamide (LSD) usage (altered thoughts, feelings, and awareness of one's surroundings), this compound is very attractive to hallucinogenic substances users.

Methods An exhaustive literature search was carried out in PubMed, Google Scholar and other biomedical data bases without limiting period, to identify relevant articles.

Results Despite frequent recreational use, knowledge about the 25C-NBOMe action and toxic and fatal consequences is still very limited. Most data on this drug come from clinical reports, from cases of acute fatal and non-fatal intoxications. Some animal and in vitro studies indicated a route of metabolism of the drug in the body. The drug and its metabolites were also detected in human blood and urine using combinations of chromatographic separation and mass spectrometry detection.

Conclusions Overall, findings show that $25 \mathrm{C}-\mathrm{NBOMe}$ is a powerful hallucinogen. Easy online availability, low prize and the lack of knowledge of 25C-NBOMe makes this substance potentially very dangerous to its users. Thus, further investigation on the mechanism of action, chemical, pharmacological and toxicological properties is needed to evaluate $25 \mathrm{C}-\mathrm{NBOMe}$ potential harmful effects.
\end{abstract}

Keywords $25 \mathrm{C}-\mathrm{NBOMe} \cdot$ Hallucinogen $\cdot$ Novel psychoactive substance $\cdot$ Legal highs $\cdot$ Designer drug

\section{Introduction}

According to the European Drug Reports from last years, the use of novel psychoactive substances (NPS) popularly known as legal highs, designer drugs or research chemicals, rapidly increased among young people [1]. $\mathrm{N}$-Methoxybenzyls (NBOMes) are a new group of toxic phenylethylamine derivatives of the $2 \mathrm{C}$ family compounds with $\mathrm{N}$-2-methoxy-benzyl substituted by the methoxy group at the 2- and 5-positions and a halogen atom attached to $\mathrm{C} 4$ of the phenyl ring. Low prize on the market and an easy access

Katarzyna Kamińska

katarzyna1.kaminska@uj.edu.pl

1 Jagiellonian Centre for Experimental Therapeutics (JCET), Jagiellonian University in Krakow, Bobrzynskiego 14, 30-348 Krakow, Poland

2 Faculty of Chemistry, Jagiellonian University in Krakow, Gronostajowa 2, 30-387 Krakow, Poland via the internet caused that NBOMes are potentially very dangerous agents; however, their pharmacological properties, mechanism of action, metabolism, and toxicity have not been yet fully recognised. It is know that NBOMes potently interact with serotonin $5-\mathrm{HT}_{2 \mathrm{~A}}, 5-\mathrm{HT}_{2 \mathrm{~B}}, 5-\mathrm{HT}_{2 \mathrm{C}}$ receptors, adrenergic $\alpha_{1}$ receptors and dopaminergic $\mathrm{D}_{1}$ receptors, but have lower affinity at $5-\mathrm{HT}_{1 \mathrm{~A}}$ receptor [2]. All agents of the NBOMes group exhibit low nanomolar affinity for $5-\mathrm{HT}_{2 \mathrm{~A}}$ receptors which is higher in comparison to other $2 \mathrm{C}$ compounds [3]. This affinity correlates with NBOMes hallucinogenic potency in humans [4]. Moreover, 5- $\mathrm{HT}_{1 \mathrm{~A}}$ receptor stimulation has been hypothesized to counteract hallucinogenic activity and in consequence a lower $5-\mathrm{HT}_{1 \mathrm{~A}}$ receptor stimulation for the NBOMes compounds may further enhance their hallucinogenic properties [5].

25C-NBOMe [ $N$-(2-methoxybenzyl)-2, 5-dimethoxy4-chlorophenethylamine] known also as NBOMe-2C-C, 2C-C-NBOMe C-Boom, 25C, legal acid, NBomb, NEBOME, Pandora, Dime, NBOMe-2C-C, BOM, 2-C-Cor, 
Cimbi-82 began to be sold via online sites in 2010 but its use was not reported in the scientific literature until 2011 [6]. The effect of 25C-NBOMe usage is characterized by various psychiatric and physiological effects like hallucination [7], violent agitation, euphoria, insomnia, rhabdomyolysis and kidney injury. 25C-NBOMe has effects similar to those of lysergic acid diethylamide (LSD) and according to some media reports LSD users may often unwittingly ingest 25C-NBOMe, instead of LSD [8].

The present study provides a brief review on available data about 25C-NBOMe chemical structure and properties, widely understood biological effects of its intake and analytical methods used for identification of this compounds in humans.

\section{Chemical characterisation}

Published data about chemical characterisation of $25 \mathrm{C}-\mathrm{NBOMe}$ is very limited so far. 25C-NBOMe contains the substructure of 4-chloro-2, 5-dimethoxyphenethylamine $(2 \mathrm{C}-\mathrm{C})$, substituted with the $N$-(2-methoxy) benzyl group (Fig. 1). The molecular formula of 25C-NBOMe is $\mathrm{C}_{18} \mathrm{H}_{22} \mathrm{ClNO}_{3}$ and the molecular weight of free base is 335.8 . 25C-NBOMe does not have chiral centres and thus does not form stereoisomers [9].

There are several chemical names for 25C-NBOMe, the most commonly use are 2-(4-chloro-2, 5 -dimethoxyphenyl)- $N$-(2-methoxybenzyl) ethanamine, 2-(4-chloro-2, 5-dimethoxyphenyl)- $N$-(2-methoxybenzyl) ethan-1-amine, Cimbi-82 (11C radiolabelled for PET

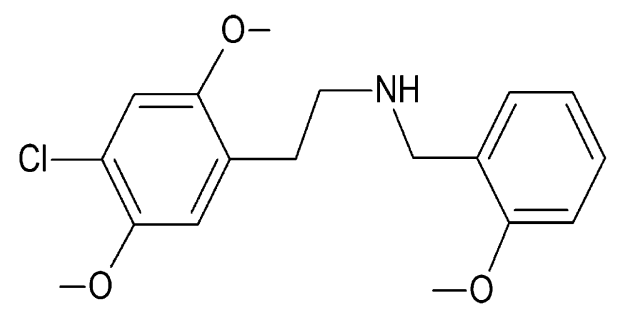

Fig. 1 Chemical structure of 25C-NBOMe
scanning)_Center for Integrated Molecular Brain Imaging (CIMBI).

The synthesis of 25C-NBOMe, schematically illustrated in Fig. 2, follows the process described by Heim in 2003 [10].

\section{Pharmacological characterisation}

25C-NBOMe acts as a potent partial agonist for the $5-\mathrm{HT}_{2 \mathrm{~A}}$ serotonin receptor with binding affinity of $2.89 \pm 1.05 \mathrm{nM}$ in vitro [11]. Stimulation of the $5-\mathrm{HT}_{2 \mathrm{~A}}$ receptors is essential for the hallucinogenic effects of drugs $[12,13]$. Limited studies using animal experiments have shown that 25C-NBOMe induced a head twitch response of a behavioural marker of hallucinogenic effects induced by activation of the $5-\mathrm{HT}_{\mathrm{A} 2}$ receptor [14]. In the work of $\mathrm{Xu}$ et al. 25C-NBOMe was tested in vitro against neuroblastoma human cell line $\mathrm{SH}$ SY5Y, PC12-cell line derived from a pheochromocytoma of the rat adrenal medulla, and a mouse neuron-like dopaminergic cell line SN4741 to evaluate neurotoxic effects of the drug. The cells were treated with 25C-NBOMe $(25-400 \mu \mathrm{M})$ and measured after $24 \mathrm{~h}$ by the in vitro cytotoxicity assay with MTT dye (MTT) a colorimetric assay for assessing cell metabolic activity [15]. It was found that concentrations above $100 \mu \mathrm{M}$ of 25C-NBOMe significantly decreased cell viability in all three cell lines. An increased apoptotic process was observed only for SN4741 cells suggesting preferentially potent neurotoxicity of $25 \mathrm{C}-\mathrm{NBOMe}$ in the dopamine cells. $\mathrm{Xu}$ and co-workers also showed that 25C-NBOMe concentration of $50 \mu \mathrm{M}$ inhibited activities of phosphorylated Akt-kinase (pAkt) and pSer9 (GSK3b Antibody)-Glycogen synthase kinase 3 beta (GSK3 $\beta$ ) and enhanced expression of pERK. Thus 25C-NBOMe may produce in vitro neurotoxicity via a PI3-K/Akt pathway inhibition and the activation of the extracellular signal-regulated kinase (ERK) signaling pathway cascade by agonist action on 5-HT ${ }_{2 \mathrm{~A}}$ ERK $[15,16]$. Gatch and co-workers have reported in their work that administration of 25C-NBOMe $(0.5,1,2.5$, and $5 \mathrm{mg} / \mathrm{kg})$ resulted in time- and dosedependent locomotor activity depression with depressant effects occurred within 10 min after injection which lasted
Fig. 2 Schematic of the 25I-NBOMe synthesis process

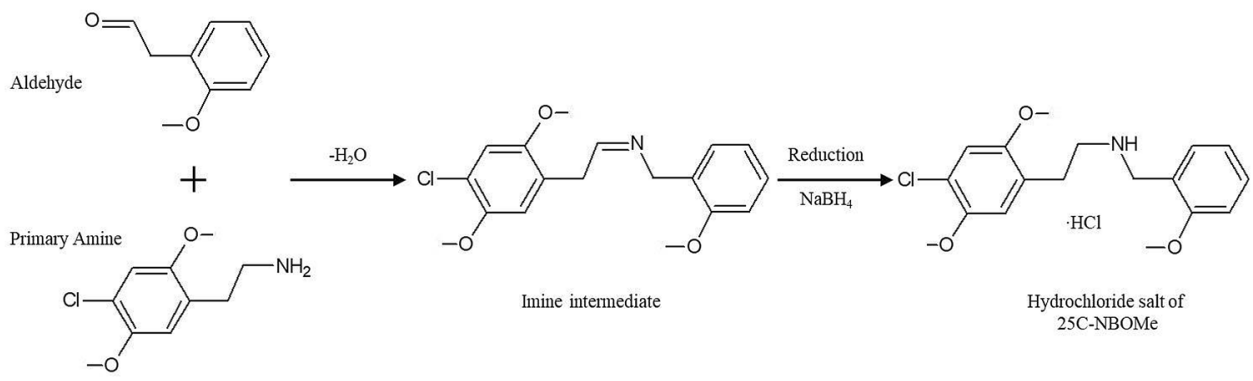


30-60 min [17]. Moreover, 25C-NBOMe (0.5, 1, 2.5, and $5 \mathrm{mg} / \mathrm{kg}$ ) generated substantial fluctuations in drug-appropriate responding with maximum effects of approaching $80 \%$ drug-appropriate responding. To our best knowledge there is no data about the abuse potential of 25C-NBOMe neither in animals or in humans. Importantly, these novel hallucinogen is extremely potent and psychoactive at microgram doses when taken buccally, administrated sublingually and insufflated.

Wohlfarth et al. have demonstrated in in vitro and in vivo studies that $25 \mathrm{C}-\mathrm{NBOMe}$ is metabolized by $O$-demethylation, $O$-di-demethylation and hydroxylation. According to authors, all methoxy groups in 25C-NBOMe could be demethylated with hydroxylation preferably occurred at the NBOMe ring [18]. Furthermore, phase I metabolites were extensively conjugated with glucuronic acid and sulfate in human urine [18]. Caspara et al., have investigated the metabolism of 25C-NBOMe in rats and humans using liquid chromatography coupled to mass spectrometry highresolution [19]. 25C-NBOMe was metabolized by $O$-demethylation, $O, O$-bis-demethylation and hydroxylation. Sixty nine phase I metabolites were identified. Most metabolites were common for all investigated spieces but $N$-dealkylated, $O$-demethylated metabolites and various isomers of $O$, $O$-bis-demethyl-hydroxy metabolites were detected in rat urine only [19].

\section{Effects of 25C-NBOMe intake}

According to internet web sites dedicated to the hallucinogenic substances users-Erowid, 25-NBOMe acts as an active hallucinogen agent at a dose of $200-500 \mu \mathrm{g}$ when insufflated. The users described effects as light for 50-200 $\mu \mathrm{g}$, mild for $200-350 \mu \mathrm{g}$, strong for 350-700 $\mu \mathrm{g}$, and very strong after intake of higher doses. Three hundred to six hundred $\mu \mathrm{g}$ doses taken buccally are only one third potency of LSD (2C-C-NBOMe Dose-Erowid). When administered sublingually, the threshold for the onset of hallucinogenic effects reportedly is about $100-250 \mu \mathrm{g}$, with mild, strong, and very strong effects after $250-450,450-800$, and over $800 \mu \mathrm{g}$, respectively [20, 21]. Overdose of 25C-NBOMe have been linked to hospitalizations due to multi-organ failures and deaths $[22,23]$.

\section{Applied analytical methods}

Non-fatal case studies have reported various psychiatric and physiological effects of 25C-NBOMe intake, like hallucination [7], violent agitation, euphoria, insomnia, rhabdomyolysis and kidney injury, tachycardia, hypertension, seizures, hyperpyrexia [24]. Zygowiec et al. have described a case of a 27-year-old male with confirmed ingestion of a psychoactive substance. High-performance liquid chromatography-tandem mass spectrometry (HPLC-MS/MS) detected 25C-NBOMe, 25H-NBOMe and 25B-NBOMe in blood samples with concentrations above the $0.50 \mathrm{ng} / \mathrm{mL}$ reporting limits [25]. Rajotte et al. have described toxicological analyses including 25C-NBOMe in a drug-impaired driver. Gas chromatography-mass spectrometry (GC-MS) showed a mass spectral identification of this agent [26]. First the driver urine sample was analysed by two immunoassay panels screened for low concentration of psychoactive substances. GC-MS was performed for beta-hydroxybutyrate $(20 \mathrm{mg} / \mathrm{L})$ and gamma-hydroxybutyrate $(2.5 \mathrm{mg} / \mathrm{L})$ analysis. The only positive drug finding from these analyses was an NBOMe compound. Retrospectively, the detected compound was identified as 25C-NBOMe [26]. A young male died in a hospital approximately $12 \mathrm{~h}$ after the use of the psychoactive substance. The death was preceded by hallucinations and convulsions. A hospital examination showed a wild spectrum of physiological effects. 25C-NBOMe and its demethylated and glucuronidated metabolites were identified in urine and whole blood using ultra-performance liquid chromatography with high-resolution time-of-flight mass spectrometry (UPLC-HRTOF-MS) and ultra-performance liquid chromatography with tandem mass spectrometry (UPLC-MS/MS) [27]. The limit of detection and lower limit of quantification were $0.02 \mathrm{mg} / \mathrm{kg}$ and $0.08 \mathrm{mg} / \mathrm{kg}$, respectively [27]. In turn Murini and co-workers have reported a case of a teenager male who was found dead in a waterway after jumping off into water stream [28]. The death occurred by drowning but to evaluate the potential role of psychoactive substances the toxicological exams were performed. Peripheral and central blood as well urine samples were collected and analysed by liquid chromatography tandem mass spectrometric (LC-MS/MS). The method was linear over the range from 0.1 to $5.0 \mathrm{ng} / \mathrm{mL}$. Accuracy and imprecision were measured, calibration curve used in this at two different quality controls $(0.2$ and $1.0 \mathrm{ng} / \mathrm{mL})$ and were found to be within the $15 \%$. Five $25-\mathrm{NBOMes}$, including 25C-NBOMe, were identified in the samples [28]. An accidental death of a 23-year-old male has been reported by Kristofic et al. A fast liquid chromatography quadrupole time-of-flight mass spectrometry (LC-QTOF-MS) with a basic solid-phase extraction was employed to isolate 25C-NBOMe, $25 \mathrm{C}-\mathrm{NBOH}$ and $2 \mathrm{C}-\mathrm{C}$ from blood and urine specimens. An LC-MS/MS analysis exhibited the presence of $25 \mathrm{C}-\mathrm{NBOMe}$ and $2 \mathrm{C}-\mathrm{C}$ in blood and urine samples The QTOF mass spectrometer was operated in positive electrospray ionization mode utilizing MSE acquisition, which permits simultaneous acquisition under low collision energy and high collision energy functions [29]. Similarly, Soh and Ellion have showed two fatal cases in which a possible metabolite of 25C-NBOMe was detected in blood and urine [30]. Detection and identification 
Table 1 Effect of 25C-NBOMe intake, analytical methods and the result of the real sample analysis

The effect of 25-NBOMe intake

Psychiatric effects

Positive effects: mental stimulation, physical stimulation, creative thinking, mood lift, open and closed eye visuals, increased awareness, lifechanging spiritual experiences, euphoria [8]

Negative effects: general change in consciousness, pupil dilation, difficulty focusing, unusual body sensations, change in perception of time, slight increase in heart rate, hot flushes and/or cold chills [8]

Neutral effects: nausea, insomnia, paranoia, fear, panic, unwanted and overwhelming feelings, unwanted life-changing spiritual experiences [8]

Physiological effects

Organ injuries: rhabdomyolysis and kidney injury [24]

Cardiological effects: tachycardia, hypertension, seizures, hyperpyrexia [24]

Other: dry mucous membranes and skin [25], bleeding from all mucosa, respiratory and metabolic acidosis, high lactic acid, anuria, hyperthermia, hyperkalaemia [27]

Analytical methods

High performance liquid chromatography: tandem mass spectrometry (HPLC-MS/MS)

Gas chromatography: mass spectrometry (GC-MS)

Ultra: performance liquid chromatography with high-resolution time-of-flight mass spectrometry (UPLC-HRTOF-MS)

Ultra-performance liquid chromatography with tandem mass spectrometry (UPLC-MS/MS)

Liquid chromatography tandem mass spectrometric (LC-MS/MS)

Fast liquid chromatography quadrupole time-of-flight mass spectrometry (LC-QTOF-MS)

Ultra high performance liquid chromatography with high mass accuracy quadrupole time-of-flight mass spectrometry (UHPLC-Q-TOF-MS)

High performance liquid chromatography with diode-array detection (HPLC-DAD)

Liquid chromatography with mass spectrometry (LC-MS)

Fourier-transform infrared spectrometry (FTIR)

Nuclear magnetic resonance spectroscopy (NMR)

Result of the real sample analysis (25-NBOMe examples concentration in biological samples by different analytical methods)

Blood samples

Peripheral blood: $2.80 \mathrm{ng} / \mathrm{mL}$ by LC-MS/MS [28]

Central blood: $1.43 \mathrm{ng} / \mathrm{mL}$ by LC-MS/MS [28]

Post-mortem peripheral blood: $0.60 \mathrm{mg} / \mathrm{kg}$ by UPLC-HRTOF-MS and UPLC-MS/MS [27]

Ante-mortem whole blood: $0.81 \mathrm{mg} / \mathrm{kg}$ by UPLC-HRTOF-MS and UPLC-MS/MS [27]

Urine samples

Urine: $0.94 \mathrm{ng} / \mathrm{mL}$ by LC-MS/MS [28]

Liver

Liver: $0.82 \mathrm{mg} / \mathrm{kg}$ by UPLC-HRTOF-MS and UPLC-MS/MS [27]

Liver: $15.2 \mathrm{ng} / \mathrm{g}$ by LC-QTOF-MS and LC-MS/MS [29]

Gastric content

Gastric sample: $0.32 \mathrm{mg}$ by UPLC-HRTOF-MS and UPLC-MS/MS [27]

Gastric contents: $30.2 \mu \mathrm{g}$ total in $100 \mathrm{~mL}$ by LC-QTOF-MS and LC-MS/MS [29]

Vitreous humour samples

Vitreous humor: $0.33 \mathrm{mg} / \mathrm{kg}$ UPLC-HRTOF-MS and UPLC-MS/MS [27]

Brain

Brain: $19.1 \mathrm{ng} / \mathrm{g}$ by LC-QTOF-MS and LC-MS/MS [29]

Spleen

Spleen: $27.1 \mathrm{ng} / \mathrm{g}$ by LC-QTOF-MS and LC-MS/MS [29]

Lungs

Lung: $25.2 \mathrm{ng} / \mathrm{g}$ by LC-QTOF-MS and LC-MS/MS [29]

Kidneys

Kidney: $25.1 \mathrm{ng} / \mathrm{g}$ by LC-QTOF-MS and LC-MS/MS [29] 
of 25C-NBOMe were carried out using high-performance liquid chromatography with diode-array detection (HPLCDAD), LC-MS/MS and ultra high performance liquid chromatography with high mass accuracy quadrupole time-offlight mass spectrometry (UHPLC-Q-TOF-MS) [30].

Till now 25C-NBOMe was identified in ante-mortem and post-mortem samples of whole blood, liver, urine, gastric content, and vitreous humour samples [27]. Zuba and co-workers have proposed analytical procedures for the identification of 25C-NBOMe in blotter papers originating from the drug market [20]. Several analytical techniques were applied to detect this drug such as GC-MS with and without derivatization with trifluoroacetic anhydride, liquid chromatography with mass spectrometry (LC-MS), Fouriertransform infrared spectrometry (FTIR) and nuclear magnetic resonance (NMR) spectroscopy [31]. The dominant ions, representatives of 25-NBOMe series in GC-MS spectrum of 25C-NBOMe were observed at $m / z=121,150$ and 91 [31]. The FTIR spectrum of the sample was recorded in the $600-4000 \mathrm{~cm}^{-1}$ rang. The strong peaks assigned to $\mathrm{C}-\mathrm{O}-\mathrm{C}$ (25-NBOMe series, are characterized by the asymmetric $\mathrm{C}-\mathrm{O}-\mathrm{C}$ stretch vibrations near) vibrations were observed at $1036 \mathrm{~cm}^{-1}, 1215 \mathrm{~cm}^{-1}$ and $1252 \mathrm{~cm}^{-1}$ [31]. In case of NMR spectroscopy, the signals in the $1 \mathrm{H}$ and $13 \mathrm{C}$ spectra were assigned on the basis of one- and two-dimensional homoand heteronuclear experiments [20].

The table below shows the effect of 25C-NBOMe intake, analytical methods and the result of the real sample analysis (Table 1).

\section{Conclusions}

The case studies clearly indicated that the exposure on 25C-NBOMe leads to fatal and non-fatal intoxication of its users and it can be unwittingly ingest instead of LSD. However, a number of NBOMe-related intoxications and deaths could be underestimated due to the lack of proper and sensitive analytical methods. Despite the fact of recognised fatal cases there is still a lack of experimental studies explaining the mechanism of its action and providing information about pharmacological properties and toxicity. Although adverse effects of 25C-NBOMe are known, long-lasting and chronical usage effects have not been recognised so far. To overcome these issues and to develop analytical procedures of identification of this toxic agent further extensive studies on the 25C-NBOMe action are urgently needed.

\section{Compliance with ethical standards}

Conflict of interest The authors declare that he has no conflict of interest.

Ethical approval This article does not contain any studies with human participants performed by the authors.

Open Access This article is licensed under a Creative Commons Attribution 4.0 International License, which permits use, sharing, adaptation, distribution and reproduction in any medium or format, as long as you give appropriate credit to the original author(s) and the source, provide a link to the Creative Commons licence, and indicate if changes were made. The images or other third party material in this article are included in the article's Creative Commons licence, unless indicated otherwise in a credit line to the material. If material is not included in the article's Creative Commons licence and your intended use is not permitted by statutory regulation or exceeds the permitted use, you will need to obtain permission directly from the copyright holder. To view a copy of this licence, visit http://creativecommons.org/licenses/by/4.0/.

\section{References}

1. United Nation Office on Drugs and Crime. (2019) The World Drug Report 2019. https://wdr.unodc.org/wdr2019. Accessed 2 Oct 2019

2. Rickli A, Luethi D, Reinisch J, Buchy D et al (2015) Receptor interaction profiles of novel $\mathrm{N}$-2-methoxybenzyl (NBOMe) derivatives of 2,5-dimethoxy-substituted phenethylamines (2C drugs). Neuropharmacology 99:546-553

3. Nichols DE (2016) Psychedelics. Pharmacol Rev 68(2):264-355

4. Halberstadt AL (2017) Hallucinogenic drugs: a new study answers old questions about LSD. Curr Biol 27:156-158

5. Nichols DE (2004) Hallucinogens. Pharmacol Ther 101(2):131-181

6. UNODC (2018) Executive summary conclusions and policy implications. World Drug Report 2018

7. Srisuma S, Bronstein AC, Hoyte ChO (2015) NBOMe and 2C substitute phenylethylamine exposures reported to the National Poison Data System. Clin Toxicol (Phila) 53(7):624-628

8. Erowid (2019) NBOMes sold as LSD/Acid testing3.shtml. https ://www.erowid.org/chemicals/lsd/lsd. Accessed 2 Oct 2019

9. Critical Report 25C-NBOMe Agenda item 4.18 Expert Committee on Drug Dependence. Thirty-sixth meeting geneva, 16-20 June 2014

10. Heim R, Elz S (2000) Novel extremely potent partial 5-HT2Areceptor agonists: successful application of a new structure- activity concept. Arch Pharmaz Pharm Med Chem 333:18-39

11. Ettrup A, Hansen M, Santini MA, Paine J, Gillings N, Palner M et al (2011) Radiosynthesis and in vivo evaluation of a series of substituted 11C-phenethylamines as 5-HT (2A) agonist PET tracers. Eur J Nucl Med Mol Imaging 38:681-693

12. Marek GJ, Aghajanian GK (1996) LSD and the phenethylamine hallucinogen are potent partial agonists at 5-HT2A receptors on interneurons in rat piriform cortex. J Pharmacol Exp Ther 278(3):1373-1382

13. Gonzalez- Maeso J, Sealfon SC (2009) Psychodelics and schizophrenia. Trend Neurosci 32:225-232

14. Bersani FS, Corazza O, Albano G, Valeriani G, Santacroce R et al (2014) 25C-NBOMe: preliminary data on pharmacology, psychoactive effects, and toxicity of a new potent and dangerous hallucinogenic drug. Bio Med Res Int 6:734-749 
15. Xu P, Qiu Q, Li H, Yan S et al (2019) 25C-NBOMe, a novel designer psychedelic, induces neurotoxicity 50 times more potent than methamphetamine in vitro. Neurotox Res 35:993-998

16. Aringhieri S, Kolachalam S, Gerace C, Carli M, Verdesca V, Brunacci MG, Rossi C, Ippolito C, Solini A, Corsini GU, Scarselli M (2017) Clozapine as the most efficacious antipsychotic for activating ERK 1/2 kinases: role of 5-HT2A receptor agonism. Eur Neuropsychopharmacol 27(4):383-398

17. Gatch MB, Dolan SB, Forster MJ (2017) Locomotor and discriminative stimulus effects of four novel hallucinogens in rodents. Behav Pharmacol 28(5):375-385

18. Wohlfarth A, Roman M, Andersson M, Kugelberg FC et al (2017) 25C-NBOMe and 25I-NBOMe metabolite studies in human hepatocytes, in vivo mouse and human urine with high-resolution mass spectrometry. Drug Test Anal 9:680-698

19. Caspara AT, Brandtb SD, Stoeverc AE, Meyera MR et al (2017) Metabolic fate and detectability of the new psychoactive substances2-(4-bromo-2,5-dimethoxyphenyl)- $\mathrm{N}$-[(2-methoxyphenyl)methyl]ethanamine (25B-NBOMe) and 2-(4-chloro2,5-dimethoxyphenyl)-N-[(2-methoxyphenyl)methyl]ethanamine (25C-NBOMe) in human and raturine by GC-MS, LC-MSn, and LC-HR-MS/MS approaches. J Phar Biomed Anal 134:158-169

20. Zuba D, Sekua K, Buczek A (2013) 25C-NBOMe-new potent hallucinogenic substance identified on the drug market. Forensic Sci Int 227:7-14

21. Kyriakou C, Marinelli E, Frati P, Santurro A et al (2015) NBOMe: new potent hallucinogens-pharmacology, analytical methods, toxicities, fatalities: a review. Eur Rev Med Pharm Sci 19:3270-3281

22. Grautoff S, Kähler J (2014) Lebensgefährliche Intoxikation mit der neuen psychoaktiven substanz 25C-NBOMe. Med Klin Intensivmed Notfmed 109:271-275
23. Tarpgaard M, Maerkedahl R, Lauridsen K (2015) Fatal intoxication with the new designer drug 25C-NBOMe. Wkly J Phys $177: 35$

24. Nefcy A, Wilson J, Smith MP, Maso K, Bora K (2013) Which reality is this? A novel PCP analog combined with $2 \mathrm{C}-\mathrm{NBOMe}$ causes a dissociative serotonin syndrome. Clin Tox 251(7):665-689

25. Zygowiec J, Solomon S, Jaworski A, Bloome M, Gotlib A (2017) MD25C-NBOMe ingestion. Clin Pract Cases Emerg Med 4:295-297

26. Rajotte JW, lmentier JP, Wallage H (2017) Drug recognition evaluation and chemical confirmation of a 25C-NBOMe-impaired driver. J Forensic Sci 62(5):1410-1413

27. Andreasen MF, Telving R, Rosendal I, Eg MB et al (2015) A fatal poisoning involving 25C-NBOMe. Forensic Sci Int 251:1-8

28. Morinia L, Berninib M, Vezzolib S, Restoric M et al (2017) Death after 25C-NBOMe and 25H-NBOMe consumption. Forensic Sci Int 279:1-6

29. Kristofic J, Chmiel J, Jackson G, Vorce S et al (2016) Detection of 25C-NBOMe in three related cases. J Anal Tox 40:466-472

30. Soh YNA, Elliott S (2013) An investigation of the stability of emerging new psychoactive substances. Drug Test Anal 6(7-8):696-704

31. Coelho Neto J (2015) Rapid detection of NBOME's and other NPS on blotter papers by direct ATR-FTIR spectrometry. Forensic Sci Int 252:87-92

Publisher's Note Springer Nature remains neutral with regard to jurisdictional claims in published maps and institutional affiliations. 